\title{
Using space-time cube to analyze trends in adverse birth outcomes and maternal characteristics in Massachusetts, USA
}

\author{
Yelena Ogneva-Himmelberger $(\mathbb{D} \cdot$ Madeleine Haynes
}

Accepted: 25 January 2021 / Published online: 10 February 2021

(C) The Author(s), under exclusive licence to Springer Nature B.V. part of Springer Nature 2021

\begin{abstract}
Rates of preterm births $(<37$ gestational weeks) and low birthweight $(\leq 2500 \mathrm{~g})$ are rising throughout the United States. This study uses singleton live birth data, Empirical Bayes approach, spacetime cube and Mann-Kendall statistic to evaluate temporal trends in these adverse birth outcomes (ABO) and maternal characteristics over 15 years (2000-2014) at the census tract level for non-Hispanic white and black women in Massachusetts. In addition to analyzing trends for each variable individually, the study analyzes spatial coincidence of trends to determine which maternal characteristics exhibited trends that most strongly correlated with the $\mathrm{ABO}$ trends. The 15-year average rate of $\mathrm{ABO}$ was $7.34 \%$ for white women, and $12.05 \%$ for black women. Results show that more census tracts exhibited an increasing trend than decreasing trend in birth outcomes and in several maternal characteristics for both races (gestational and chronic hypertension, gestational diabetes, and previous preterm birth). Study identified 52 census tracts concurrently experiencing an increasing trend in $\mathrm{ABO}$ and in four maternal characteristics for black women, indicating that multiple negative trends in health
\end{abstract}

Supplementary Information The online version supplementary material available at https://doi.org/10.1007/ s10708-021-10382-w.

Y. Ogneva-Himmelberger $(\square) \cdot$ M. Haynes Clark University, 950 Main St., Worcester, MA, USA

e-mail: yogneva@clarku.edu outcomes are concentrated at the same location creating a potential for even more adverse outcomes in the future. This study provides a novel, spatially explicit analytical framework based on Empirical Bayes rates and space-time cube, which could be extended to analyze trends in other health outcomes at various spatial scales.

Keywords Adverse birth outcomes - Preterm birth . Low birthweight $\cdot$ Maternal health $\cdot$ Space-time cube . Mann-Kendall

\section{Introduction}

Rates of adverse birth outcomes (ABO), which are comprised of both preterm births $(<37$ gestational weeks) and low birthweight $(\leq 2500 \mathrm{~g})$ are unfortunately rising throughout the United States. The rate of preterm births (PTB) in the USA in 2018 was $10.02 \%$ (up from $9.57 \%$ in 2014) while the rate of low birthweight (LBW) has also increased from $8.00 \%$ in 2014 to $8.28 \%$ in 2018 (Martin et al. 2019). The causes underlying the rise in $\mathrm{ABO}$ rates are not well understood. Potential hypotheses include elevated use of cesarean deliveries and induced labor, assisted conception methods, and elevated age of women who are conceiving (Beck et al. 2010; March of Dimes 
2013; American College of Obstetricians and Gynecologists 2020; Institute of Medicine 2007).

\section{Literature review}

Previous studies evaluating $\mathrm{ABO}$ typically rely on multivariate regression to understand the role that an individual woman's health and socioeconomic status may have on the likelihood of an ABO. Results found that women with diabetes, hypertension (pre-existing and pregnancy related), substance use (drugs, alcohol, and tobacco), who had a previous $\mathrm{ABO}$, and those of lower socioeconomic status have an increased risk (Berghella 2007; Goldenberg and Culhane 2007; American College of Obstetricians and Gynecologists 2020; Honein et al. 2009; Soneji and Beltrán-Sánchez 2019).

Health risks associated with an $\mathrm{ABO}$ include an increased likelihood of respiratory problems, brain hemorrhage, heart complications, cerebral palsy, learning disabilities, delayed motor and social skills, and an increased likelihood of infant mortality (Clark et al. 2009; March of Dimes 2013; Rosenthal and Lobel 2011). Aside from the complex issue presented by the multi-faceted causative factors, there is also a well-documented racial disparity in ABOs that has yet to be fully understood (Burris and Hacker 2017; Kent et al. 2013; Lu and Halfon 2003; Centers for Disease Control and Prevention 2016). In the US the rates of PTB and LBW in 2018 in black women were 14.13 and $14.07 \%$, while for white women they were 9.09 and $6.91 \%$ respectively (Martin et al. 2019).

As an increase in both PTB and LBW has been documented, it is important to consider both the spatial and temporal components when examining ABOs. Although previous studies have investigated correlations between health or socioeconomic variables and $\mathrm{ABO}$ rates, none have comparatively evaluated temporal trends in both $\mathrm{ABO}$ rates and individual-level health variables spatially at a statewide scale for over a decade worth of individual level data. Major gaps in the literature exist around evaluating temporal trends to further understand how and why $\mathrm{ABO}$ rates are increasing.

A common method of evaluating temporal trend is the use of the Mann-Kendall statistic. It is calculated by comparing the value at each time step for each unit of analysis (e.g., town or census tract) to that of the prior time step to identify statistically significant increases or decreases over time (Abdrakhmanov et al. 2017; ESRI 2019; Kendall 1948). A trend's significance is determined based on the calculated $\mathrm{Z}$ score and the $\mathrm{p}$ value of the Mann-Kendall statistic.

To calculate the Mann-Kendall statistic in a GIS context, the space-time cube functionality within the ArcGIS software allows for analysis of both the spatial and temporal dimensions of data (Gatalsky et al. 2004; Ross et al. 2019). The GIS-based space-time cube analysis has been used in recent health studies, including the analysis of small for gestational age and low birth weight at term in Canada (Nielsen et al. 2019, 2020), hemorrhagic fever with renal syndrome (Zhao et al. 2019) and COVID-19 in China (Mo et al. 2020), and anthrax epidemic in livestock in Kazakhstan (Abdrakhmanov et al. 2017).

The output from the Mann-Kendall statistic is a spatial layer showing each spatial unit belonging to one of the seven categories: increasing trend (>99\% confidence; p-value $<0.01)$, increasing trend (95-99\% confidence; $0.01<$ p-value $<0.05$ ), increasing trend $(90-95 \%$ confidence; $0.05<\mathrm{p}$ value $<0.1$ ), decreasing trend $(>99 \%$ confidence; p-value $<0.01$ ), decreasing trend $(95-99 \%$ confidence; $0.01<\mathrm{p}$-value $<0.05)$, decreasing trend (90-95\% confidence; $0.05<\mathrm{p}$-value $<0.1$ ), and no significant trend.

To address existing gaps in literature on ABOs, specifically, the lack of temporal trend analysis, this study seeks to: (1) use GIS techniques to evaluate temporal trends in both $\mathrm{ABO}$ rates and individuallevel variables across the state of Massachusetts, (2) examine the spatial relationship between trends in $\mathrm{ABO}$ and trends in maternal characteristics. Massachusetts is an ideal location to study ABO trends as socioeconomic and demographic characteristics range widely from the predominantly rural west to the densely populated metropolitan east. Additionally, the size of the state allows for comprehensive spatial analysis at a census tract level.

\section{Materials and methods}

The study obtained ethics approval by the Institutional Review Boards of our University (project ID 2018-017) and Massachusetts Department of Public Health (project ID 2009044). Birth data, geocoded to 
census block, was provided by the Massachusetts Department of Public Health for 2000-2014. Six percent of births lacked census block information and were excluded from the analysis. For this analysis, only singleton, live births to non-Hispanic white and non-Hispanic black women were included. We chose non-Hispanic white and non-Hispanic black women because racial disparities in birth outcomes are the most striking between these two racial groups. Information on the gestational age and the birth weight was used to determine if the birth was an $\mathrm{ABO}$. If a birth was either a PTB or LBW (or both) it was categorized as an $\mathrm{ABO}$. Each birth was coded with geographical location and the baby's birth date allowing for both spatial and temporal analysis.

To enable the spatial analysis of birth data, we first mapped individual births at the corresponding census block centroid, using 2000 Census boundaries for 2000-2009 births, and 2010 Census boundaries for 2010-2014 births. Then we spatially joined birth data (as points) to 2010 census tract boundaries and calculated the number of births in each category for each year (total number, PTB, and LBW births). The aggregation of individual births to census tracts was necessary due to small numbers of births in some areas. Census block and tract boundaries were downloaded from the Office of Geographic Information, Commonwealth of Massachusetts (https://www.mass. gov/mgis/massgis.htm). There are 1472 census tracts in Massachusetts, with average population of 4448 people per census tract. The size of 2010 census tracts varied between 0.043 and 516.4 sq.km, with the median of 3.9 sq.km and mean of 14.2 sq.km.

Birth data also contained specific individual-level information such as the woman's race/ethnicity, whether she had gestational diabetes, hypertension (chronic or gestational), a previous PTB, or if she smoked during pregnancy. This data is self-reported by women. We included these variables in the analysis because of their importance for birth outcomes. Using this data, we calculated for each census tract, for each year, separately for non-Hispanic black and nonHispanic white women, the percentage of women who had these health conditions and percent of women $<$ 20 years old and women $\geq 35$ years old.

Additionally, ABO rates were calculated for each census tract for each year [(LBW + PTB births)/total births]. We combined LBW and PTB together in our analysis to examine overall trends in $\mathrm{ABO}$ in order to alleviate the "small number problem". This problem arises when the denominator (total number of births) is small, which is common in sparsely populated rural areas. To account for potential biases that arise when dealing with "small numbers", these rates were smoothed using Empirical Bayesian Smoothing (EBS), a common approach for dealing with variance instability. This approach works by combining the $\mathrm{ABO}$ rate with prior information, such as the mean ABO rate for the entire state (Anselin et al. 2006). The EBS rates are arguably more robust and reliable than the raw rates (Cressie 2010; Chen et al. 2006). EBS rates were also calculated for the seven individuallevel variables for each census tract, for each year, separately for the two races.

Two space-time cubes, one per race, were constructed in ArcGIS to evaluate trends in $\mathrm{ABO}$ rates and rates of individual-level variables for the 15-year study period. The space-time cube is a three-dimensional object which allows for visualization and analysis in both the spatial (horizontal) and temporal (vertical) dimensions. The cubes were constructed such that each census tract was an individual unit of analysis in the spatial dimension and each year was the unit of analysis in the temporal dimension. Sixty census tracts that had no births over the study period were not included in the space-time cube, so there were no missing data and no empty bins in the spacetime cubes. Since ABO EBS rates were already calculated for individual years, no additional statistics were calculated for each bin during the construction of space-time cubes.

A Mann-Kendall trend score was calculated and assigned for each census tract within the space-time cube from one of seven possible categories (three increasing trend categories, three decreasing trend categories, and no significant trend category). These seven categorizations were further simplified to increasing $(p<0.1)$, decreasing $(p<0.1)$ and no statistically significant trend. This process was repeated for all seven individual-level variables, for each census tract.

To determine areas where $\mathrm{ABO}$ trends were occurring in the same location as a trend in the individual-level variables, the Mann-Kendall trend categorizations were cross-tabulated to further examine relationships between the trends. Through this process, a total number of nine pairwise combinations were possible, and the number of tracts in each 
combination was calculated. For this analysis, we were interested in tracts that exhibited an increasing $\mathrm{ABO}$ trend and increasing individual-level variable trend. Isolating these areas of concern can help to identify priority locations for public health interventions, especially for the behavioral or health outcomes that are preventable.

\section{Results}

Our study included a total of 725,582 births to white women, and 92,295 births to black women. This distribution of births reflects the proportional distribution of white and black females in the state: $80 \%$ of female population is white, and $6.7 \%$ is black (ESRI 2010). The 15 -year average ABO rate was $7.34 \%$ for white women, and $12.05 \%$ for black women.

The space-time cubes consisted of 1418 census tracts and 15 time slices, corresponding to 15 years of data. Figure 1 shows a section of the space-time cube for $\mathrm{ABO}$ rates. Small cubes stacked on top of each other, represent the $\mathrm{ABO}$ rate for a tract over time, with the year 2000 at the bottom and the year 2014 at the top of the bin time series.

Looking at this figure, one can notice that some locations exhibit clear increasing (lighter to darker colors) or decreasing (darker to lighter colors) trends, while others show a sporadic change in colors from one year to the next, with no clear trend. Using the Mann-Kendall statistic allows for identification of the statistically significant monotonous trends (increasing or decreasing), and we focus our analysis on these areas.

The majority of the 1418 census tracts did not exhibit a statistically significant $(\mathrm{p}<0.1)$ decreasing or increasing trend in $\mathrm{ABO}$ or individual-level variables for both races (Table 1). For example, 87-88\% of tracts did not show a trend for ABOs. Census tracts that showed trends were not concentrated in certain areas but rather distributed in a random fashion through the entire state for all variables (Figs. 2, 3). While maps provide visual representation of trends, it is also important to compare the number of census tracts exhibiting trends for each variable. These comparisons are meaningful because census tracts, by design, include approximately the same population count. The following section discusses trends in ABOs
Fig. 1 A section of the space-time cube for adverse birth outcomes rates for white women. Each colored column (bin time series) is positioned at the population-adjusted centroid of corresponding census tract

and each individual-level variable as summarized in Table 1.

The number of tracts with an increasing $\mathrm{ABO}$ rate were slightly higher for white (116) than for black (104) women. The decreasing ABO trend presented an opposite pattern - the number of tracts was higher for black (84) than for white women (54). For both races, more tracts exhibited increasing trend than decreasing trend. Interestingly, tracks with decreasing trends in black $\mathrm{ABO}$ have considerably higher proportion of black females than tracts with increasing trends in black $\mathrm{ABO}-13$ vs. $3.4 \%$. On the other hand, there was no difference in proportion of white women in the tracts with increasing/decreasing white $\mathrm{ABO}$ - in both cases $81 \%$ of female population was white.

Trends in cigarette use during pregnancy showed encouraging results-for both races, there were 4-5 times more tracts with a decreasing trend than with an increasing trend. Decreasing trends were more widespread among black women with almost twice as many census tracts exhibiting this trend (326) than for white women (188).

Trends in gestational hypertension were similar for both races - there were twice as many tracts with an increasing trend than with a decreasing trend, and the numbers in each category were comparable (e.g., for increasing trend, 148 for white, and 123 for black). Conversely, chronic hypertension trends were very different: 3.4 times more tracts showed increasing trend for white women (612) compared to black women (179). In fact, increasing chronic hypertension trends in white women had more tracts (612) exhibiting a trend (either increasing or decreasing) for all variables for both races. This is also evident in Fig. 3-the map for chronic hypertension is the "reddest" map (indicating increasing trends) when compared to the other maps. Tracts with decreasing trends for this variable are minimal (10 for white and 36 for black).

Gestational diabetes is another variable where the number of tracts with an increasing trend were measurably higher for whites than blacks, in this case almost two times higher (384 vs. 199). Like chronic 


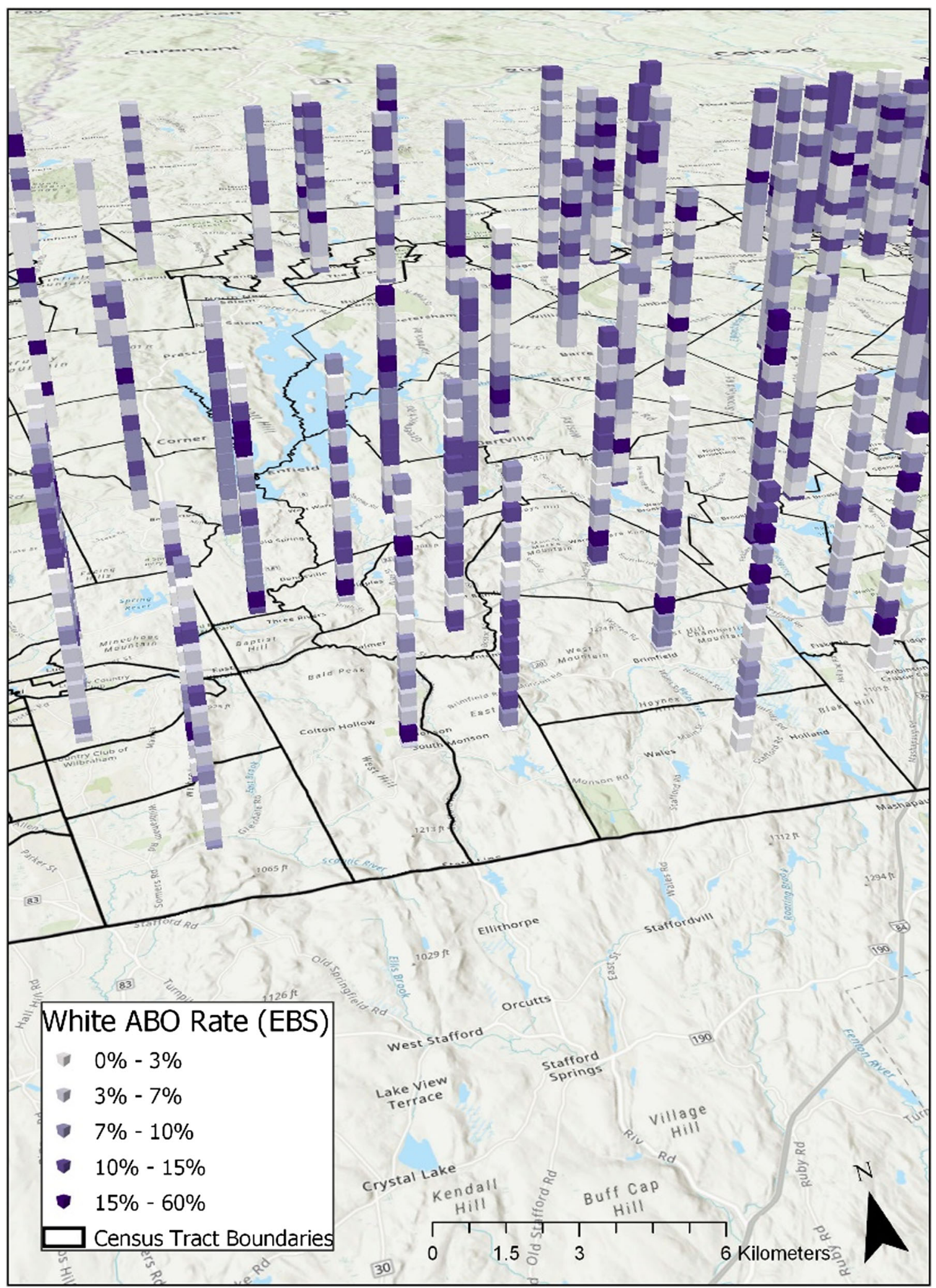


Table 1 Number of census tracts with statistically significant ( $\mathrm{p}$-value $<0.1$ ) decreasing trend, increasing trend or no trend for births to non-Hispanic white and non-Hispanic black women

\begin{tabular}{|c|c|c|c|}
\hline Variable & Trend & White & Black \\
\hline \multirow[t]{3}{*}{$\mathrm{ABO}$ rate } & Decreasing & 54 & 84 \\
\hline & No trend & 1248 & 1230 \\
\hline & Increasing & 116 & 104 \\
\hline \multirow[t]{3}{*}{ Cigarette use rate } & Decreasing & 188 & 326 \\
\hline & No trend & 1187 & 1033 \\
\hline & Increasing & 43 & 58 \\
\hline \multirow[t]{3}{*}{ Gestational hypertension rate } & Decreasing & 62 & 59 \\
\hline & No Trend & 1208 & 1236 \\
\hline & Increasing & 148 & 123 \\
\hline \multirow[t]{3}{*}{ Chronic hypertension rate } & Decreasing & 10 & 36 \\
\hline & No trend & 796 & 1203 \\
\hline & Increasing & 612 & 179 \\
\hline \multirow[t]{3}{*}{ Gestational diabetes rate } & Decreasing & 8 & 26 \\
\hline & No trend & 1026 & 1193 \\
\hline & Increasing & 384 & 199 \\
\hline \multirow[t]{3}{*}{ Previous preterm birth rate } & Decreasing & 39 & 69 \\
\hline & No trend & 824 & 1205 \\
\hline & Increasing & 555 & 148 \\
\hline \multirow[t]{3}{*}{ Woman's age $\geq 35$ rate } & Decreasing & 177 & 19 \\
\hline & No trend & 1131 & 1144 \\
\hline & Increasing & 110 & 255 \\
\hline \multirow[t]{3}{*}{ Woman's age $<20$ rate } & Decreasing & 429 & 291 \\
\hline & No trend & 961 & 1064 \\
\hline & Increasing & 28 & 63 \\
\hline
\end{tabular}

hypertension, the number of tracts with a decreasing trend was also small ( 8 for white and 26 for black). Previous preterm delivery trends are also dissimilar between races; 3.75 times more tracts had increasing trend among white women (555) than black women (148). Decreasing trends were present in a much smaller number of tracts-39 for white, and 69 for black.

Two variables related to the woman's age presented very different patterns. For the percent women $\geq 35$ years old, far more tracts showed a decreasing trend for white women (177) than for black women (19). The opposite is true for those with an increasing trend, in which there were 255 tracts for black and 110 tracts for white women. Percent of women $<20$ years old is the only variable that showed strong decreasing trends for both races. The number of tracts with a decreasing trend for whites is 429 , the highest number of tracts with a decreasing trend among all variables and both races, while only 291 for blacks. Figure 3 illustrates this very clearly - the map for women $<20$ years old has more blue colored areas (representing a decreasing trend) than any other map.

In addition to examining trends for each variable individually, we analyzed spatial coincidence of trends to determine which maternal characteristics exhibited trends that most strongly correlated with the $\mathrm{ABO}$ trends. Of particular interest are the areas where an increasing trend in $\mathrm{ABO}$ coincided with an increasing trend in maternal characteristics. The following section describes cross-tabulation results presented in Tables 2 and 3 and Figs. 4 and 5.

Maps of these coincidence patterns (Figs. 4, 5) have two colors to highlight areas where the same trend happens simultaneously in both variables, with red colored tracts corresponding to the bottom right cell in the $3 \times 3$ matrix for each variable in Tables 2 and 3 (intersection of row and column labelled "increasing"), and blue colored tracts corresponding to the top left cell in the $3 \times 3$ matrix (intersection of row and column labelled "decreasing"). Grey colored tracts correspond to the other seven cells in each of the $3 \times 3$ matrices where trends differ between ABOs and maternal characteristics.

Of 104 tracts with increasing $\mathrm{ABO}$ trend for black women (Table 1), 84 tracts $(81 \%)$ also had an increasing trend in gestational diabetes, 82 tracts (79\%) also had an increasing trend in chronic hypertension, 81 tracts $(78 \%)$ also had an increasing trend in previous preterm births, 79 tracts $(76 \%)$ also had an increasing trend in women of age $\geq 35$, and 73 tracts (70\%) also had an increasing trend in gestational hypertension.

A subsequent analysis of tracts for black women showed that there were 52 tracts concurrently experiencing an increasing trend in $\mathrm{ABO}$ and in four individual-level variables, illustrating the deteriorating health outcomes despite better medical understanding and technology. This indicates that multiple negative trends in health outcomes are concentrated at the same location for black women creating a potential for even more adverse outcomes in the future. These 52 tracts, located in 41 towns, should be the focus of 
Fig. 2 Trends in adverse birth outcomes and individual-level variables for Black women
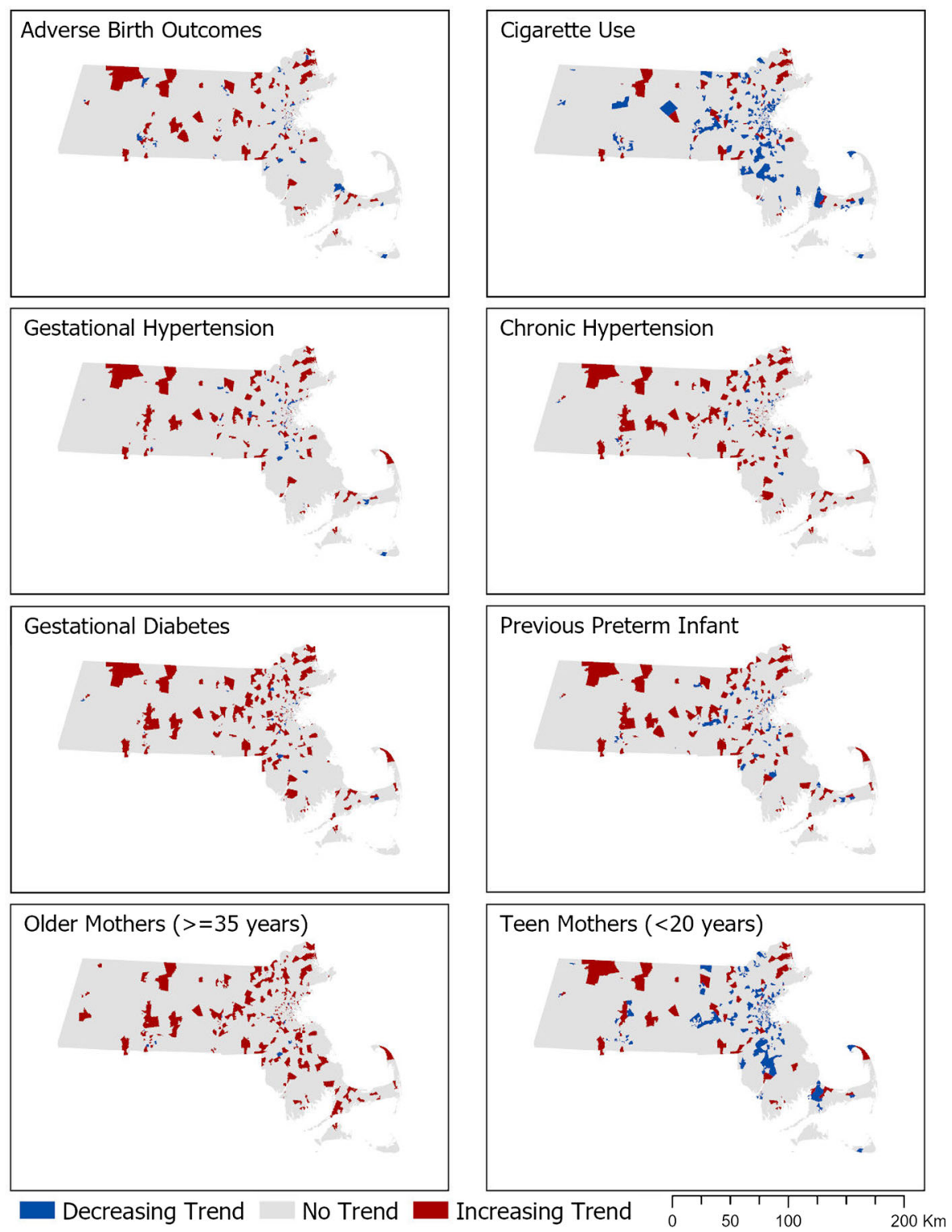

attention of local public health professionals and physicians (Supplemental material).

The degree of spatial coincidence between decreasing trends in $\mathrm{ABO}$ and individual-level variables for black women is much lower when compared to the coincidence in increasing trends. Only two variables stood out - cigarette use and women $<20$ years old. Of the 84 tracts with a decreasing $\mathrm{ABO}$ trend, 51 $(61 \%)$ also showed a decreasing trend in cigarette use, and $44(52 \%)$ showed a decreasing trend in women $<$ 20 years old.
ABO trends in white women revealed far less spatial agreement with trends in maternal characteristics compared to black women. This can be observed on the maps-Fig. 5 has fewer red and blue colored tracts than Fig. 4 therefore indicating far less spatial coincidence between ABOs and maternal level variables. Of the 116 tracts with increasing ABO trends, $61(53 \%)$ also had an increasing trend in chronic hypertension, and 57 (49\%) had an increasing trend in previous preterm birth. The other five maternal characteristics showed no trend in the majority of these 116 tracts. 

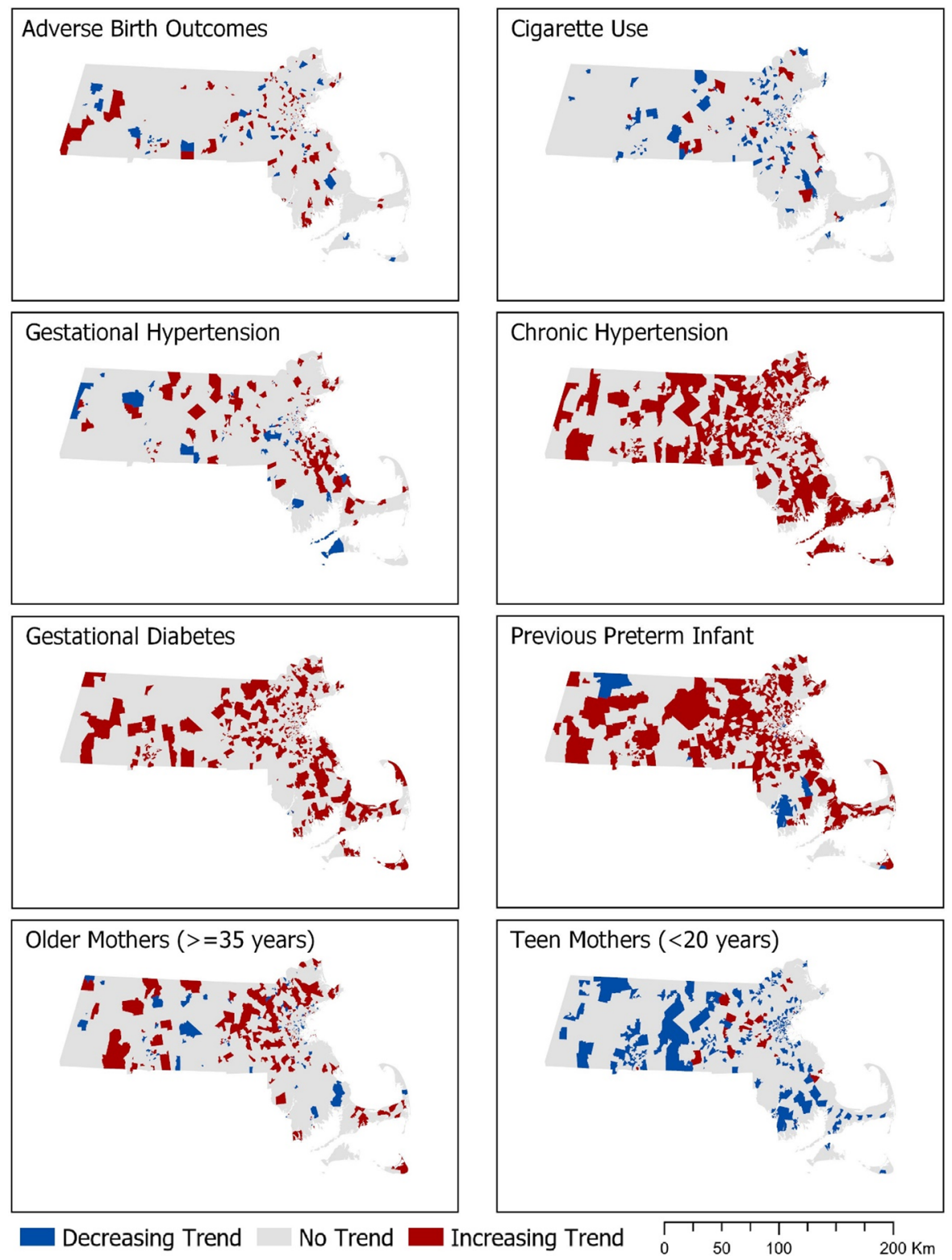

Fig. 3 Trends in adverse birth outcomes and individual-level variables for White women

\section{Discussion}

We applied innovative spatio-temporal analysis techniques to the study of trends in ABO in the State of Massachusetts. Our study is the first to use EBS rates in space-time cube analysis of health outcomes. We found that more census tracts exhibited an increasing trend than a decreasing trend for $\mathrm{ABO}$ and four maternal level health variables (gestational diabetes, gestational and chronic hypertension, and previous
PTB), for both white and black women in Massachusetts. These findings are alarming because these fours health conditions are known to increase the risk of $\mathrm{ABO}$.

Of concern is the magnitude of the increasing trends in gestational diabetes and chronic hypertension, especially among white women. Massachusetts Department of Public Health reports an almost twofold increase in gestational diabetes among all women between 2000 and 2014, from 2.8 to $5.4 \%$. Our study 
Table 2 Co-occurrence of trends in $\mathrm{ABO}$ and individual-level variables for black women
The most notable cooccurrences are highlighted in bold

${ }^{\mathrm{a}}$ The number of census tracts with a particular trend type

${ }^{\mathrm{b}}$ The number and percent of census tracts in each crosstabulation category

\begin{tabular}{|c|c|c|c|c|}
\hline \multicolumn{2}{|c|}{ Variables and trend type } & Decreasing & No trend & Increasing \\
\hline & & \multicolumn{3}{|c|}{ Prior preterm birth rate } \\
\hline \multirow[t]{4}{*}{$\mathrm{ABO}$ rate } & Decreasing $(\mathrm{n}=84)^{\mathrm{a}}$ & $24(29 \%)^{\mathrm{b}}$ & $6071 \%)$ & $0(0 \%)$ \\
\hline & No trend $(\mathrm{n}=1230)$ & $56(5 \%)$ & $1116(91 \%)$ & $58(4 \%)$ \\
\hline & Increasing $(n=104)$ & $3(3 \%)$ & $20(19 \%)$ & $81(78 \%)$ \\
\hline & & \multicolumn{3}{|c|}{ Woman's age $\geq 35$ rate } \\
\hline \multirow[t]{4}{*}{$\mathrm{ABO}$ rate } & Decreasing $(n=84)$ & $8(10 \%)$ & $68(81 \%)$ & $8(9 \%)$ \\
\hline & No trend $(\mathrm{n}=1230)$ & $10(1 \%)$ & $1052(85 \%)$ & $168(14 \%)$ \\
\hline & Increasing $(n=104)$ & $1(1 \%)$ & $24(23 \%)$ & $79(76 \%)$ \\
\hline & & \multicolumn{3}{|c|}{ Woman's age $<20$ rate } \\
\hline \multirow[t]{4}{*}{$\mathrm{ABO}$ rate } & Decreasing $(n=84)$ & $44(52 \%)$ & $39(47 \%)$ & $1(1 \%)$ \\
\hline & No trend $(n=1230)$ & $243(20 \%)$ & $979(79 \%)$ & $8(1 \%)$ \\
\hline & Increasing $(n=104)$ & $4(4 \%)$ & $46(44 \%)$ & $54(52 \%)$ \\
\hline & & \multicolumn{3}{|c|}{ Cigarette use rate } \\
\hline \multirow[t]{4}{*}{$\mathrm{ABO}$ rate } & Decreasing $(n=84)$ & $51(61 \%)$ & $33(39 \%)$ & $0(0 \%)$ \\
\hline & No trend $(n=1230)$ & $271(22 \%)$ & $955(78 \%)$ & $4(0 \%)$ \\
\hline & Increasing $(n=104)$ & $4(4 \%)$ & $45(44 \%)$ & $54(52 \%)$ \\
\hline & & \multicolumn{3}{|c|}{ Chronic hypertension rate } \\
\hline \multirow[t]{4}{*}{$\mathrm{ABO}$ rate } & Decreasing $(n=84)$ & $12(14 \%)$ & $72(86 \%)$ & $0(0 \%)$ \\
\hline & No trend $(\mathrm{n}=1230)$ & $22(2 \%)$ & $1111(90 \%)$ & $97(8 \%)$ \\
\hline & Increasing $(n=104)$ & $2(2 \%)$ & $20(19 \%)$ & $82(79 \%)$ \\
\hline & & \multicolumn{3}{|c|}{ Gestational hypertension rate } \\
\hline \multirow[t]{4}{*}{$\mathrm{ABO}$ rate } & Decreasing $(n=84)$ & $23(28 \%)$ & $59(70 \%)$ & $2(2 \%)$ \\
\hline & No trend $(n=1230)$ & $36(3 \%)$ & $1146(93 \%)$ & $48(4 \%)$ \\
\hline & Increasing $(n=104)$ & $0(0 \%)$ & $31(30 \%)$ & $73(70 \%)$ \\
\hline & & \multicolumn{3}{|c|}{ Gestational diabetes rate } \\
\hline \multirow[t]{3}{*}{$\mathrm{ABO}$ rate } & Decreasing $(n=84)$ & $13(16 \%)$ & $69(82 \%)$ & $2(2 \%)$ \\
\hline & No trend $(n=1230)$ & $13(1 \%)$ & $1104(90 \%)$ & $113(9 \%)$ \\
\hline & Increasing $(n=104)$ & $0(0 \%)$ & $20(19 \%)$ & $84(81 \%)$ \\
\hline
\end{tabular}

supports this statistic and pinpoints areas with this alarming trend on the map. The increasing trend in gestational diabetes may be potentially attributed to changes in screening and diagnostic criteria over the study period. With more providers switching to onestep test vs. the older two-step test, more pregnant women are being diagnosed with this condition (Cheung and Moses 2018; Ferrara 2007; Huhn et al. 2018).

Two variables - cigarette use during pregnancy and women $<20$ years old-showed the highest number of tracts with a decreasing trend for both races. These findings are also supported by the official statistics. According to the report from Massachusetts Department of Public Health, percent of women who smoked during pregnancy went down from $10 \%$ in 2000 to
$6.4 \%$ in 2014 . At the same time, births to women $<20$ decreased from 25.9 to 10.6 per 1000 females ages 15-19 (Massachusetts Department of Public Health 2015).

Two recent studies used space-time cube to analyze critically ill cases of small for gestational age (SGA) and low birth weight at term (LBWT) in 19 metropolitan areas in Canada using 5 years of neonatal admission data from the Canadian Neonatal Network aggregated to postal code boundaries (Nielsen et al. 2019, 2020). The authors analyzed space-time hot spots of birth outcomes and industrial air pollutants and found associations with 21 known or suspected developmental toxicants. Our study uses space-time cube for analyzing and mapping temporal trends in birth outcomes at a fine spatial scale (census tract) over 
Table 3 Co-occurrence of trends in $\mathrm{ABO}$ and individual-level variables for white women
The most notable cooccurrences are highlighted in bold

${ }^{\mathrm{a}}$ The number of census tracts with a particular trend type

${ }^{\mathrm{b}}$ The number and percent of census tracts in each crosstabulation category

\begin{tabular}{|c|c|c|c|c|}
\hline \multicolumn{2}{|c|}{ Variables and trend type } & \multirow{2}{*}{\multicolumn{2}{|c|}{$\begin{array}{l}\text { Decreasing No trend } \\
\text { Prior preterm birth rate }\end{array}$}} & \multirow[t]{2}{*}{ Increasing } \\
\hline & & & & \\
\hline \multirow[t]{4}{*}{$\mathrm{ABO}$ rate } & Decreasing $(\mathrm{n}=54)^{\mathrm{a}}$ & $1(2 \%)^{\mathrm{b}}$ & $38(70 \%)$ & $15(28 \%)$ \\
\hline & No trend $(\mathrm{n}=1248)$ & $34(3 \%)$ & $731(58 \%)$ & $483(39 \%)$ \\
\hline & Increasing $(\mathrm{n}=116)$ & $4(4 \%)$ & $55(47 \%)$ & $57(49 \%)$ \\
\hline & & \multicolumn{3}{|c|}{ Woman's age $\geq 35$ rate } \\
\hline \multirow[t]{4}{*}{$\mathrm{ABO}$ rate } & Decreasing $(n=54)$ & $8(15 \%)$ & $42(78 \%)$ & $4(7 \%)$ \\
\hline & No trend $(n=1248)$ & $156(12 \%)$ & $996(80 \%)$ & $96(8 \%)$ \\
\hline & Increasing $(\mathrm{n}=116)$ & $13(11 \%)$ & $93(80 \%)$ & $10(9 \%)$ \\
\hline & & \multicolumn{3}{|c|}{ Woman's age $<20$ rate } \\
\hline \multirow[t]{4}{*}{$\mathrm{ABO}$ rate } & Decreasing $(n=54)$ & $20(37 \%)$ & $34(63 \%)$ & $0(0 \%)$ \\
\hline & No Trend $(\mathrm{n}=1248)$ & $385(31 \%)$ & $839(67 \%)$ & $24(2 \%)$ \\
\hline & Increasing $(\mathrm{n}=116)$ & $24(21 \%)$ & $88(76 \%)$ & $4(3 \%)$ \\
\hline & & \multicolumn{3}{|c|}{ Cigarette use rate } \\
\hline \multirow[t]{4}{*}{$\mathrm{ABO}$ rate } & Decreasing $(n=54)$ & $9(17 \%)$ & $44(82 \%)$ & $1(2 \%)$ \\
\hline & No trend $(n=1248)$ & $162(13 \%)$ & $1056(85 \%)$ & $30(2 \%)$ \\
\hline & Increasing $(\mathrm{n}=116)$ & $17(15 \%)$ & $87(75 \%)$ & $12(10 \%)$ \\
\hline & & \multicolumn{3}{|c|}{ Chronic hypertension rate } \\
\hline \multirow[t]{4}{*}{$\mathrm{ABO}$ rate } & Decreasing $(n=54)$ & $2(4 \%)$ & $38(70 \%)$ & $14(26 \%)$ \\
\hline & No trend $(n=1248)$ & $7(1 \%)$ & $704(56 \%)$ & $537(43 \%)$ \\
\hline & Increasing $(\mathrm{n}=116)$ & $1(1 \%)$ & $54(46 \%)$ & $61(53 \%)$ \\
\hline & & \multicolumn{3}{|c|}{ Gestational hypertension rate } \\
\hline \multirow[t]{4}{*}{$\mathrm{ABO}$ rate } & Decreasing $(n=54)$ & $4(7 \%)$ & $47(87 \%)$ & $3(6 \%)$ \\
\hline & No trend $(n=1248)$ & $57(4 \%)$ & $1071(86 \%)$ & $120(10 \%)$ \\
\hline & Increasing $(\mathrm{n}=116)$ & $1(1 \%)$ & $90(77 \%)$ & $25(22 \%)$ \\
\hline & & \multicolumn{3}{|c|}{ Gestational diabetes rate } \\
\hline \multirow[t]{3}{*}{$\mathrm{ABO}$ rate } & Decreasing $(n=54)$ & $0(0 \%)$ & $41(76 \%)$ & $13(24 \%)$ \\
\hline & No trend $(n=1248)$ & $7(1 \%)$ & $902(72 \%)$ & $339(27 \%)$ \\
\hline & Increasing $(\mathrm{n}=116)$ & $1(1 \%)$ & $83(71 \%)$ & $32(28 \%)$ \\
\hline
\end{tabular}

a longer period than previous studies (15 years). Our study is the first to apply simultaneous trend analysis in birth outcomes and individual-level health variables. This innovative method is generalizable and can be applied to other geographical areas and healthrelated topics.

There are several limitations related to our data sources and methodology. Birth certificates, the primary source of our data, have been criticized for various degrees of data validity (Andrade et al. 2013; Dietz et al. 2015; DiGiuseppe et al. 2002; LydonRochelle et al. 2005; Northam and Knapp 2006), including inaccuracies in coding of LBW and PTB. We combined LBW and PTB together in our analysis to examine overall trends in $\mathrm{ABO}$, though we recognize that each may have a different trend, in order to alleviate the "small number problem" and increase stability of our Empirical Bayes rates estimates. We were not able to consider the effect of the demographic shifts and changing racial segregation over 15 years on $\mathrm{ABO}$ estimates (increase in births to non-Hispanic Black immigrant women, for example), due to the lack of immigration data at a fine spatial scale. Finally, our study did not address the issue of mobility during pregnancy. Several studies on this topic found that between 5 and $25 \%$ of women moved at least once during pregnancy (Tang et al. 2018; Lara et al. 2016; Amoah et al. 2018; Pereira et al. 2016; Bell and Belanger 2012). This means that some of the locations in some space-time bins may not be representative of the entire duration of a pregnancy and may cause misleading trends in either direction. 

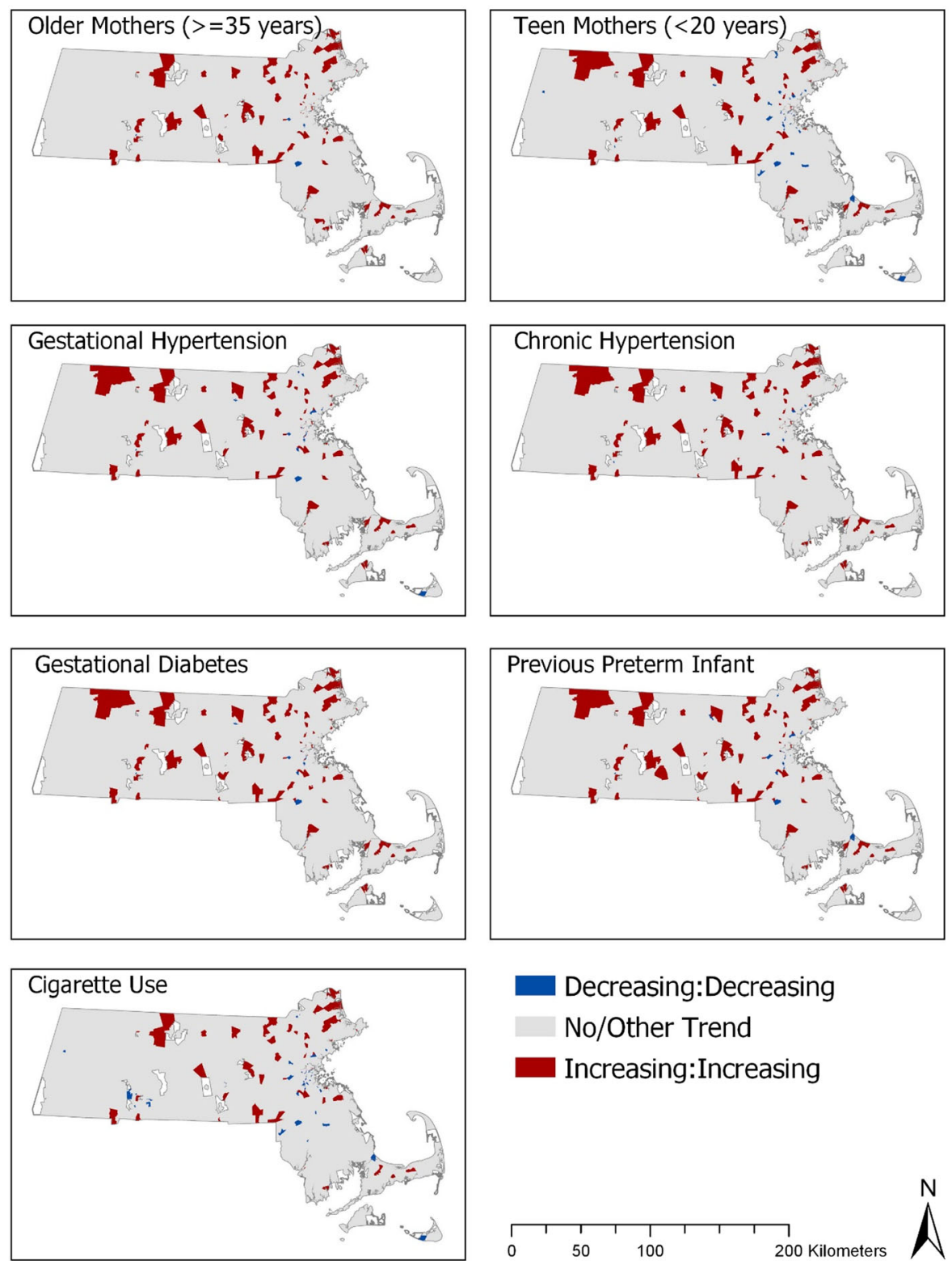

Decreasing:Decreasing

No/Other Trend

Increasing:Increasing

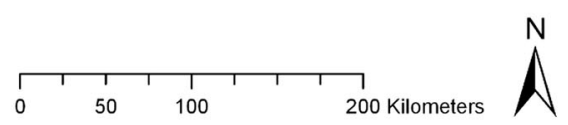

Fig. 4 Co-occurrence of trends in adverse birth outcomes and maternal factors for Black women. White areas are tracts with no births

We found that the relationship between trend patterns in ABOs and trend patterns in maternal characteristics is much stronger in black than in white women. Additionally, the identification of census tracts that were experiencing concurrent increasing tends in $\mathrm{ABO}$ and four mother-level variables for black mothers that was not seen in white mothers could be indicative of influence of other area level factors, such as poor access to health care in predominantly black neighborhoods. This finding is significant and should be studied in the future as it potentially highlights lack of understanding around factors that may be related to the difference in $\mathrm{ABO}$ rates between white and black women. This finding may be also related to the fact that our study included 7.86 times more births to white women than to black women (reflecting demographic profile of the state). The smaller number of black births per census tract in some areas could result in a less stable annual EBS rate and less reliable trend calculations. In our analysis, we 
Fig. 5 Co-occurrence of trends in adverse birth outcomes and maternal factors for White women. White areas White areas are tracts with no births
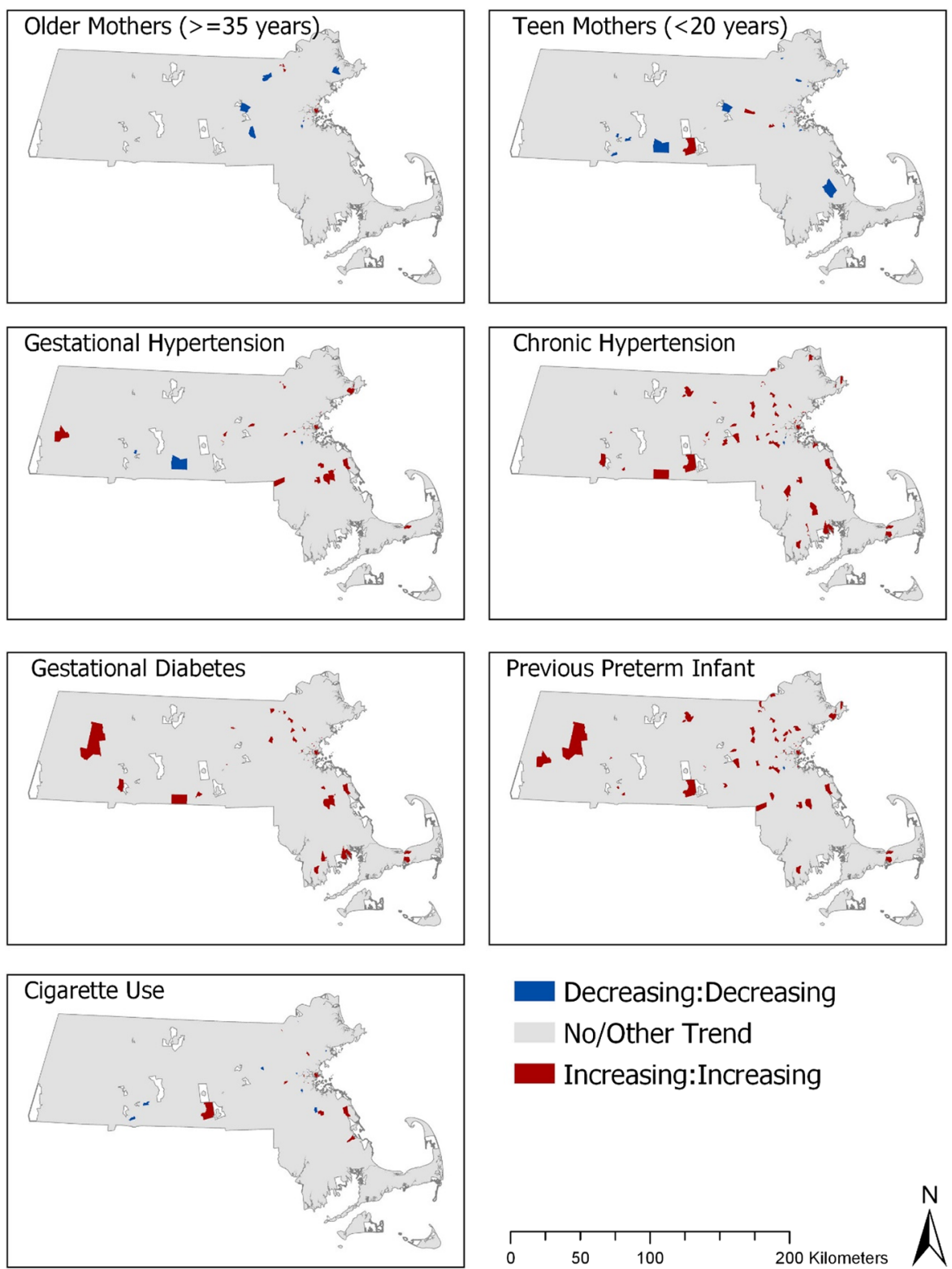

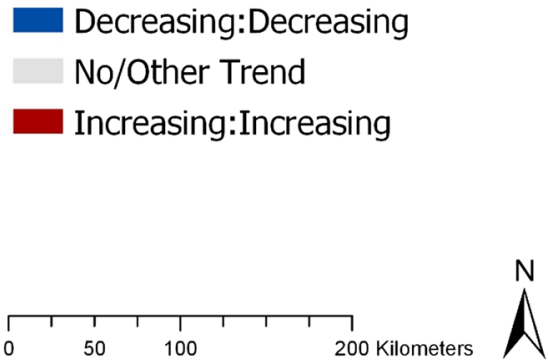

prioritized fine spatial and temporal scale (census tract and one year). As the next logical step, the future analysis would use coarser scales (towns and two years combined, for example) to study the effect of the aggregation scale on the trends in ABO and individual-level variables. Changing the spatial scale would also potentially allow analysis of PTB and LBW individually, to better understand the role that individual health variables may have on specific ABOs.

\section{Conclusions}

The study makes an important methodological contribution by providing a GIS-based framework for simultaneous trend analysis of birth outcomes and individual-level health indicators, expressed as annual EBS rates. This method can be extended to other health outcomes and other spatial scales (block groups, towns, etc.) to evaluate temporal trends and spatial patterns simultaneously. The core element of this framework, trend analysis of EBS rates with the 
space-time cube, allowed for clear identification of areas experiencing an increase in $\mathrm{ABO}$ rates and maternal characteristics which will enable more successful targeted public health evaluations and interventions at a local level.

Acknowledgements The authors wish to acknowledge David Hattis for his help with obtaining birth data for 2000-2007.

Funding This work was supported by The Leir Foundation, in memory of Henry J. and Erna D. Leir. The funding source was not involved in the study design, the collection, analysis, and interpretation of data, writing of the report and the decision to submit the article for publication.

Availability of data and material The datasets generated and analyzed during the current study are not publicly available due to HIPPA protection of individual-level health data.

\section{Compliance with ethical standards}

Conflict of interest The authors declare that they have no conflict of interest.

Ethical approval The study obtained ethics approval by the Institutional Review Boards of our University (Project ID 2018-017) and Massachusetts Department of Public Health (Project ID 2009044).

\section{References}

Abdrakhmanov, S. K., Mukhanbetkaliyev, Y. Y., Korennoy, F. I., Karatayev, B. S., Mukhanbetkaliyeva, A. A., \& Abdrakhmanova, A. S. (2017). Spatio-temporal analysis and visualisation of the anthrax epidemic situation in livestock in Kazakhstan over the period 1933-2016. Geospatial Health, 12(2), 589. https://doi.org/10.4081/gh. 2017.589.

American College of Obstetricians and Gynecologists. (2020). Preterm (premature) labor and birth. Retrived January 12, 2021, from https://www.acog.org/womens-health/faqs/ preterm-labor-and-birth.

Amoah, D. K., Nolan, V., Relyea, G., Gurney, J. G., Yu, X., Tylavsky, F. A., et al. (2018). Factors associated with residential mobility during pregnancy. Women and Health, 58(8), 955-966. https://doi.org/10.1080/03630242.2017. 1372843.

Andrade, S. E., Scott, P. E., Davis, R. L., Li, D. K., Getahun, D., Cheetham, T. C., et al. (2013). Validity of health plan and birth certificate data for pregnancy research. Pharmacoepidemiology and Drug Safety, 22(1), 7-15. https://doi. org/10.1002/pds.3319.

Anselin, L., Lozano, N., \& Koschinsky, J. (2006). Rate transformations and smoothing. Spatial Analysis Laboratory, Department of Geography, University of Illinois UrbanaChampaign. Retrived January 12, 2021, from https://www.
researchgate.net/publication/249913160_Rate_

Transformations_and_Smoothing/link/

54364d140cf2bf1f1f2b6d4d/download.

Beck, S., Wojdyla, D., Say, L., Betran, A. P., Merialdi, M., Requejo, J. H., et al. (2010). The worldwide incidence of preterm birth: A systematic review of maternal mortality and morbidity. Bulletin of the World Health Organization, 88(1), 31-38. https://doi.org/10.2471/blt.08.062554.

Bell, M. L., \& Belanger, K. (2012). Review of research on residential mobility during pregnancy: Consequences for assessment of prenatal environmental exposures. Journal of Exposure Science \& Environmental Epidemiology, 22(5), 429-438. https://doi.org/10.1038/jes.2012.42.

Berghella, V. (2007). Prevention of recurrent fetal growth restriction. Obstetrics and Gynecology, 110(4), 904-912. https://doi.org/10.1097/01.AOG.0000267203.55718.aa.

Burris, H., \& Hacker, M. (2017). Birth outcome racial disparities: A result of intersecting social and environmental factors. Seminars in Perinatology, 41(6), 360-366. https:// doi.org/10.1053/j.semperi.2017.07.002.

Centers for Disease Control and Prevention. (2016). Reproductive and birth outcomes. Retrived January 12, 2021, from https://ephtracking.cdc.gov/ showRbLBWGrowthRetardationEnv.action.

Chen, H., Stratton, H. H., Caraco, T. B., \& White, D. J. (2006). Spatiotemporal Bayesian analysis of Lyme disease in New York State, 1990-2000. Journal of Medical Entomology, 43(4), 777-784. https://doi.org/10.1093/jmedent/43.4.777.

Cheung, N. W., \& Moses, R. G. (2018). Gestational diabetes mellitus: Is it time to reconsider the diagnostic criteria? Diabetes Care, 41(7), 1337-1338. https://doi.org/10.2337/ dci18-0013.

Clark, S., Miller, D., Belfort, M., Dildy, G., Frye, D., \& Meyers, J. (2009). Neonatal and maternal outcomes associated with elective term delivery. American Journal of Obstetrics and Gynecology, 200(2), 156.e151-154. https://doi.org/10. 1016/j.ajog.2008.08.068.

Cressie, N. (2010). Smoothing regional maps using empirical Bayes predictors. Geographical Analysis, 24, 75-95. https://doi.org/10.1111/j.1538-4632.1992.tb00253.x.

Dietz, P., Bombard, J., Mulready-Ward, C., Gauthier, J., Sackoff, J., Brozicevic, P., et al. (2015). Validation of selected items on the 2003 U.S. standard certificate of live birth: New York City and Vermont. Public Health Reports, 130(1), 60-70. https://doi.org/10.1177/ 003335491513000108.

DiGiuseppe, D. L., Aron, D. C., Ranbom, L., Harper, D. L., \& Rosenthal, G. E. (2002). Reliability of birth certificate data: A multi-hospital comparison to medical records information. Maternal and Child Health Journal, 6(3), 169-179. https://doi.org/10.1023/A:1019726112597.

ESRI. (2010). 2010 Census. Retrived January 12, 2021, from https://doc.arcgis.com/en/esri-demographics/data/census. htm.

ESRI. (2019). ArcGIS Pro: How creating a space time cube works. Retrived January 12, 2021, from https://pro.arcgis. com/en/pro-app/tool-reference/space-time-patternmining/learnmorecreatecube.htm.

Ferrara, A. (2007). Increasing prevalence of gestational diabetes mellitus. A Public Health Perspective, 30(Supplement 2), S141-S146. https://doi.org/10.2337/dc07-s206. 
Gatalsky, P., Andrienko, N., \& Andrienko, G. (2004). Interactive analysis of event data using space-time cube. In: Proceedings 8th international conference on information visualisation, IV 2004, 16-16 July 2004 (pp. 145-152). https://doi.org/10.1109/IV.2004.1320137.

Goldenberg, R., \& Culhane, J. (2007). Low birth weight in the United States. American Journal of Clinical Nutrition, 85(2), 584s-590s. https://doi.org/10.1093/ajen/85.2.584S.

Honein, M., Kirby, R., Meyer, R., Xing, J., Skerrette, N., Yuskiv, N., et al. (2009). The association between major birth defects and preterm birth. Maternal and Child Health Journal, 13(2), 164-175. https://doi.org/10.1007/s10995008-0348-y.

Huhn, E. A., Rossi, S. W., Hoesli, I., \& Göbl, C. S. (2018). Controversies in screening and diagnostic criteria for gestational diabetes in early and late pregnancy. Frontiers in endocrinology, 9, 696-696. https://doi.org/10.3389/fendo. 2018.00696.

Institute of Medicine. (2007). Preterm birth: Causes, consequences, and prevention. Washington: The National Academies Press.

Kendall, M. G. (1948). Rank correlation methods (Rank correlation methods). Oxford: Griffin.

Kent, S., McClure, L., Zaitchik, B., \& Gohlke, J. (2013). Arealevel risk factors for adverse birth outcomes: Trends in urban and rural settings. BMC Pregnancy Childbirth, 13, 129. https://doi.org/10.1186/1471-2393-13-129.

Lara, D., Decker, M. J., \& Brindis, C. D. (2016). Exploring how residential mobility and migration influences teenage pregnancy in five rural communities in California: Youth and adult perceptions. Culture, Health \& Sexuality, 18(9), 980-995. https://doi.org/10.1080/13691058.2016. 1150514.

Lu, M., \& Halfon, N. (2003). Racial and ethnic disparities in birth outcomes: A life-course perspective. Maternal and Child Health Journal, 7(1), 13-30.

Lydon-Rochelle, M. T., Holt, V. L., Cárdenas, V., Nelson, J. C., Easterling, T. R., Gardella, C., et al. (2005). The reporting of pre-existing maternal medical conditions and complications of pregnancy on birth certificates and in hospital discharge data. American Journal of Obstetrics \& Gynecology, 193(1), 125-134. https://doi.org/10.1016/j.ajog. 2005.02.096.

March of Dimes, (2013). Long-term health effects of premature birth. Retrived January 12, 2021, from https://www. marchofdimes.org/complications/long-term-healtheffects-of-premature-birth.aspx.

Martin, J., Hamilton, B., Osterman, M., \& Driscoll, A. (2019). Births: Final data for 2018. National vital statistics reports (Vol. 68, No. 13). Hyattsville. Retreived January 12, 2021 from https://www.cdc.gov/nchs/data/nvsr/nvsr68/nvsr68_ 13-508.pdf

Massachusetts Department of Public Health. (2015). Massachusetts Births 2014. Retrived January 12, 2021, from https://www.mass.gov/doc/2014-report/download.
Mo, C., Tan, D., Mai, T., Bei, C., Qin, J., Pang, W., et al. (2020). An analysis of spatiotemporal pattern for COIVD-19 in China based on space-time cube. Journal of Medical Virology, 92(9), 1587-1595. https://doi.org/10.1002/jmv. 25834.

Nielsen, C. C., Amrhein, C. G., Shah, P., Aziz, K., \& OsornioVargas, Á. (2019). Spatiotemporal patterns of small for gestational age and low birth weight births and associations with land use and socioeconomic status. Environmental Health Insights, 13, 1178630219869922. https://doi.org/ 10.1177/1178630219869922.

Nielsen, C. C., Amrhein, C. G., Shah, P. S., Stieb, D. M., \& Osornio-Vargas, A. R. (2020). Space-time hot spots of critically ill small for gestational age newborns and industrial air pollutants in major metropolitan areas of Canada. Environmental Research, 186, 109472. https://doi. org/10.1016/j.envres.2020.109472.

Northam, S., \& Knapp, T. R. (2006). The reliability and validity of birth certificates. Journal of Obstetric, Gynecologic, and Neonatal Nursing, 35(1), 3-12. https://doi.org/10.1111/j. 1552-6909.2006.00016.x.

Pereira, G., Bracken, M. B., \& Bell, M. L. (2016). Particulate air pollution, fetal growth and gestational length: The influence of residential mobility in pregnancy. Environmental Research, 147, 269-274. https://doi.org/10.1016/j.envres. 2016.02.001.

Rosenthal, L., \& Lobel, M. (2011). Explaining racial disparities in adverse birth outcomes: Unique sources of stress for Black American women. Social Science \& Medicine, 72(6), 977-983. https://doi.org/10.1016/j.socscimed.2011. 01.013 .

Ross, L., Ogneva-Himmelberger, Y., \& Starr, C. (2019). The use of geographic information systems for real-time monitoring of comprehensive community initiatives. Justice Research and Policy. https://doi.org/10.1177/ 1525107119843259.

Soneji, S., \& Beltrán-Sánchez, H. (2019). Association of maternal cigarette smoking and smoking cessation with preterm birth. JAMA Network Open, 2(4), e192514e192514. https://doi.org/10.1001/jamanetworkopen.2019. 2514.

Tang, Z., Zhang, H., Bai, H., Chen, Y., Zhao, N., Zhou, M., et al. (2018). Residential mobility during pregnancy in Urban Gansu, China. Health Place, 53, 258-263. https://doi.org/ 10.1016/j.healthplace.2018.08.021.

Zhao, Y., Ge, L., Liu, J., Liu, H., Yu, L., Wang, N., et al. (2019). Analyzing hemorrhagic fever with renal syndrome in Hubei Province, China: A space-time cube-based approach. The Journal of international medical research, 47(7), 3371-3388. https://doi.org/10.1177/ 0300060519850734.

Publisher's Note Springer Nature remains neutral with regard to jurisdictional claims in published maps and institutional affiliations. 